$\underline{\text { Avicenna Journal of Nursing and Midwifery Care - ISSN 2676-5748 }}$

\title{
The Effect of Telephone Consultation and Follow-up on Pain Reduction in Multiple Sclerotic Patients: a Randomized Clinical Trial
}

\author{
Ali Bikmoradi ${ }^{1}$, Sakineh Abdolmalaki², Lily Tapak ${ }^{3}$ \\ 1. Health Economics and Management Department, School of Public Health, Hamadan University of Medical \\ Sciences, Hamadan, Iran \\ 2. Medical Surgical Department, School of Nursing and Midwifery, Hamadan University of Medical Sciences, \\ Hamadan, Iran \\ 3. Biostatistics Department, School of Public Health, Hamadan University of Medical Sciences, Hamadan, Iran
}

\begin{tabular}{ll}
\hline Article Info & ABSTRACT \\
\end{tabular}

Received: 2018/11/27;

Accepted: 2019/04/27;

Published Online: 2020/04/07

10.30699/ajnmc.28.1.11

Original Article

Use your device to scan and read the article online

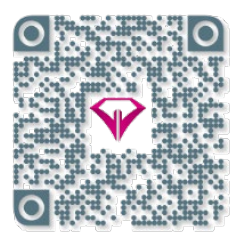

Introduction: Patients with multiple sclerosis (MS) suffer from pain. Usually, the severity of other symptoms causes the pain of these patients to be ignored or considered to be normal. This study was carried out to determine the impact of telephone counseling and follow-up on pain in patients with MS.

Methods: This randomized clinical trial was conducted on 70 MS patients attending the multiple sclerosis Clinic at Sina (Farshchian) Hospital, Hamadan, Iran. A two-month intervention was administered, with the phone calls organized as follows: Week 1 (two calls revolving around medication schedule Week 2 (two calls about a diet plan, Week 3 (two calls about the exercise schedule،Week 4 (two calls about the role of stress in MS; and Weeks 5 to 8 (four weekly reminder calls to ensure patient compliance with the contents delivered within the first 4 weeks. Pain assessment scale was completed before and after the intervention.

Results: The mean of pain severity in the experimental group before and after the consultation with telephone follow up was statistically significant $(P=0 / 001)$. The mean of pain severity in the experimental group after intervention was reduced to 4.32 with a standard deviation of 0.17 . However, the mean and standard deviation of pain in the experimental group also showed a downward trend. The comparison of the mean pain severity in the two groups after the intervention showed a significant difference $(P<0.001)$.

Conclusion: Telephone counseling together with telephone follow-up reduces pain in patients with multiple sclerosis and improves patient health. Therefore, counseling with telephone follow up is recommended in reducing pain intensity of patients.

Keywords: Telephone follow-up, Telephone counseling, Pain, Multiple sclerosis disease

\section{How to Cite This Article:}

Bikmoradi A, Abdolmaleki S, Tapak L. The Effect of Telephone Consultation and Follow-up on Pain Reduction in Multiple Sclerotic Patients: Randomized Clinical Trial. Avicenna J Nurs Midwifery care. 2020; $28(1): 11-19$ 
تأثير مشاوره همراه با ييگيرى تلفنى بر كاهش شدت درد بيماران مولتييل اسكلروزيس: يك كار آزمايى بالينى على بيكمرادى"'، سكينه عبدالمالكى ז، ليلى تاياك؟

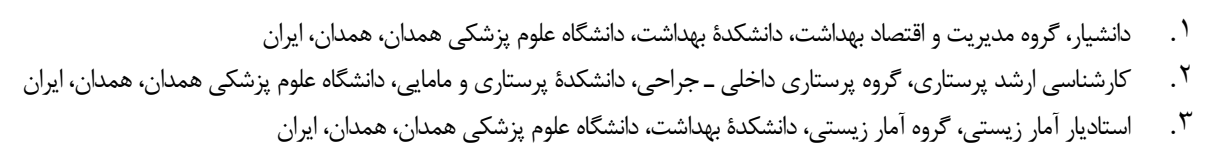

\begin{tabular}{|c|c|}
\hline جـكيده & اطلاعات مقاله \\
\hline 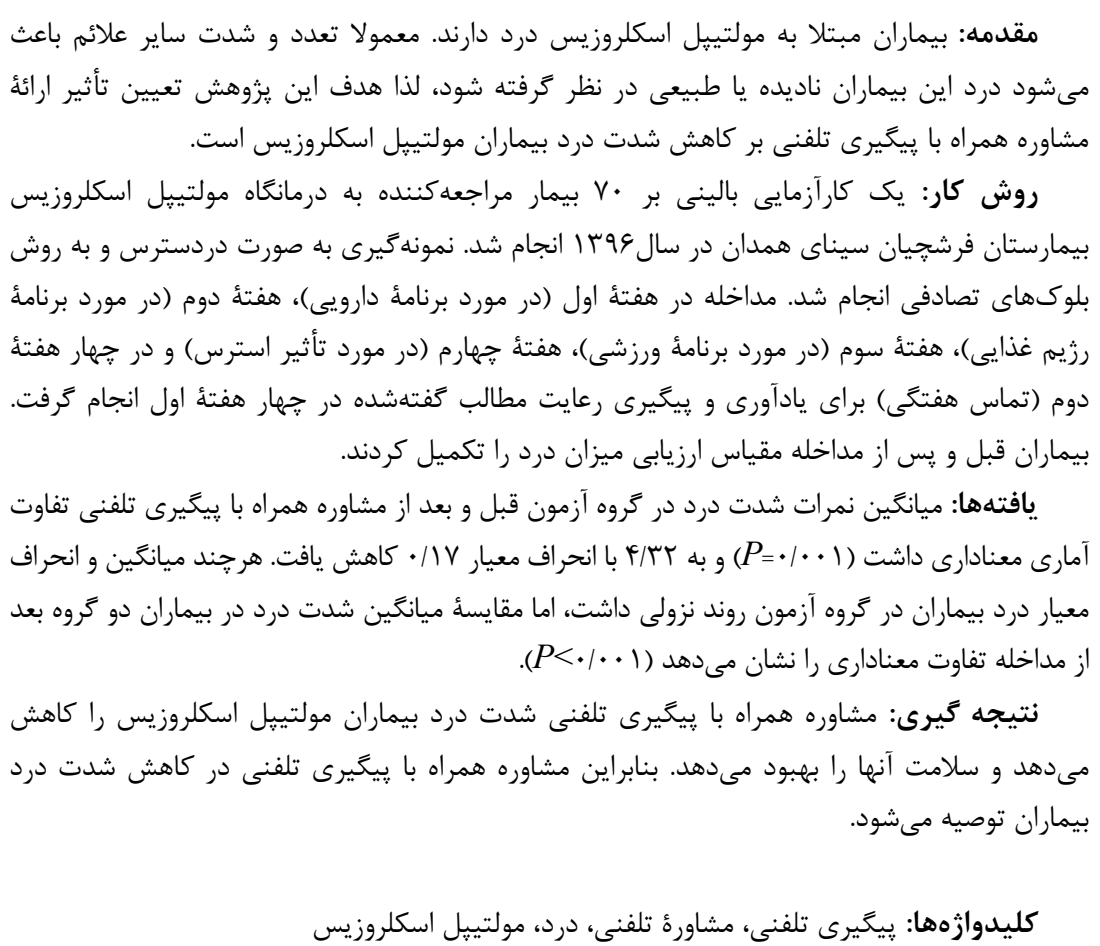 & 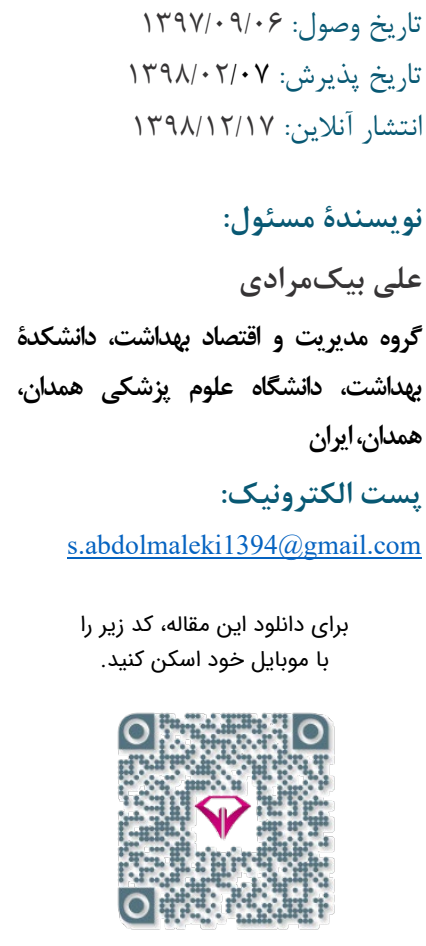 \\
\hline
\end{tabular}

مقدمه

شود، اما هر گونه صدمه به آكسون دائمى است. اخر مغز نتواند

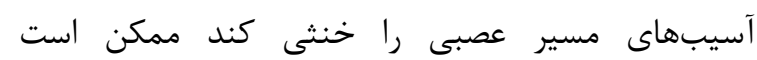
فعاليتهاى تحت كنترل آن عصب براى هميشه از دماى دست

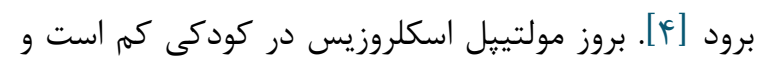

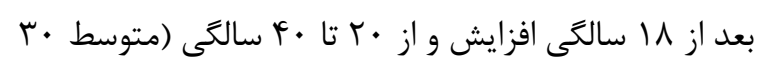

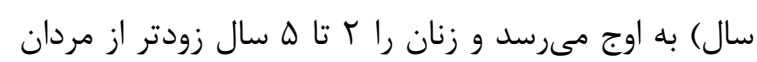
تحت تأثير قرار مىدهد [ه]. هرجند نقش عوامل زنتيكى و عوامل محيطى (ويروس،

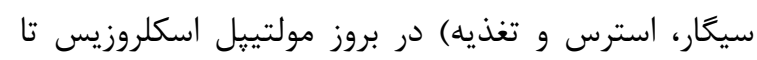
حدودى تأييد شده، ولى هنوز علت آن ناشناخته است [ع] دئ. بيمارى مولتييل اسكلروزيس با تأثير بر جنبههاى فيزيكى،

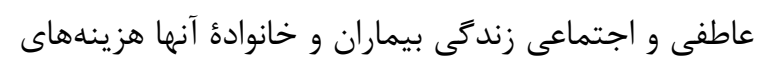

بيش از س/ץ ميليون نفر در سراسر جهان مولتييل

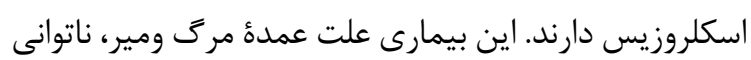

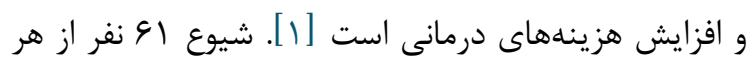

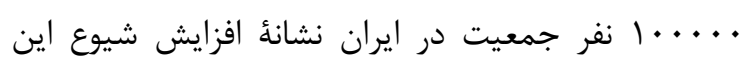
بيمارى در كشور است [ب]. مولتييل اسكلروزيس بيمارى مزمن ناتوان كننده و

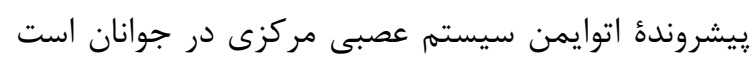

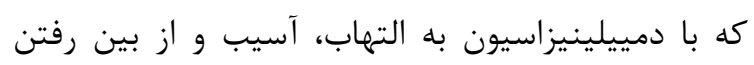

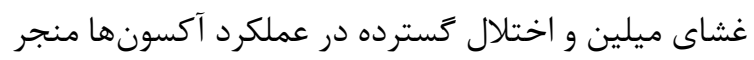

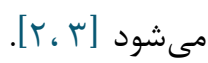
مولتييل اسكلروزيس باعث آسيب غلاف ميلين مىشود. اگرجه ممكن است آسيب غلاف ميلين تا حدودى ترميم 
عصبى است و يك تيم درمانى براى بازتوانى حداكثر توانايى بيماران نياز است [1/1].

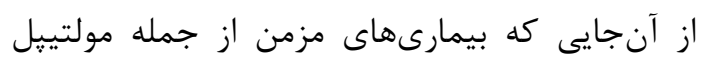

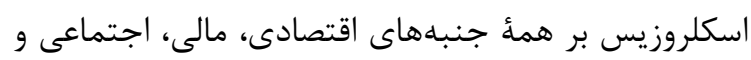
عاطفى فرد، خانواده و جامعه اثر مى تذارد، فقط درمان دارويى و كنترل دورههاى بيمارى كافى نيست و وردان يرستاران

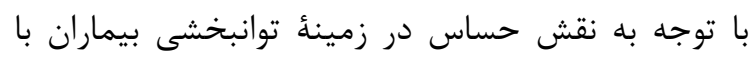
ناتوانى جسمى - روانى قادرند به آنها در بالا بردن توانايى تواني

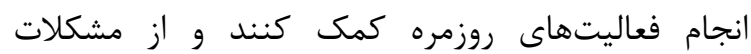

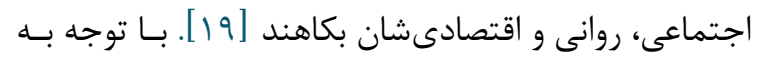

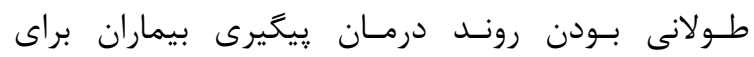

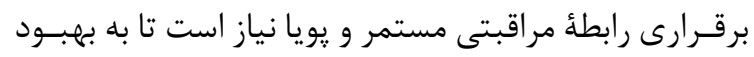

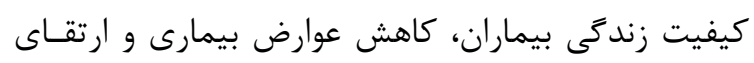

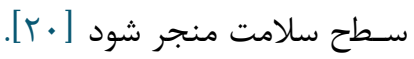
يكى از روشهـاى يُيخيرى يرستارى از راه دور اسـتفاده

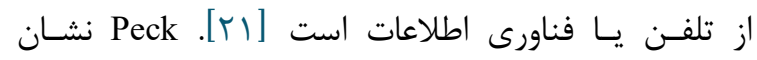
مى دهد كه يرستارى از راه دور در كاهش هزينه و تسهيل

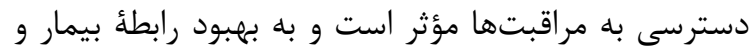

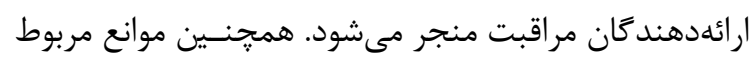

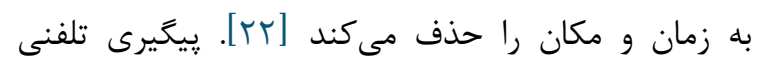

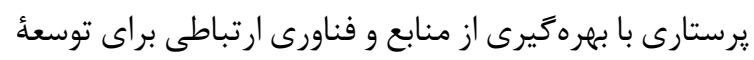

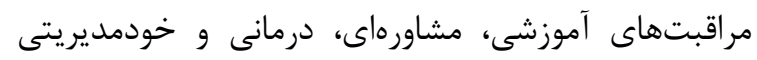

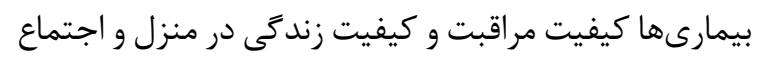

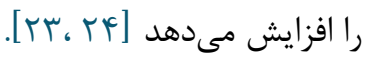
קيخيرى تلفنى يرستارى با حفظ ارتباط مستمر و ورها

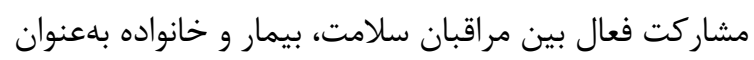

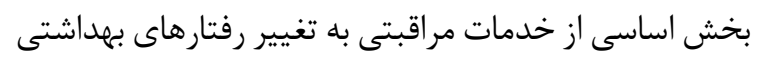

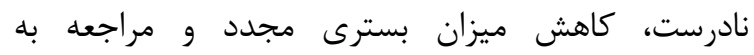

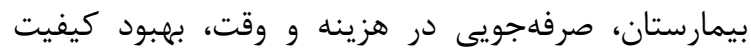

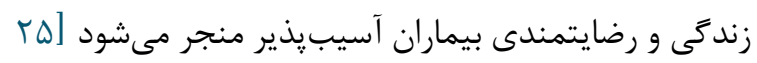

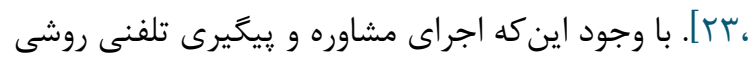

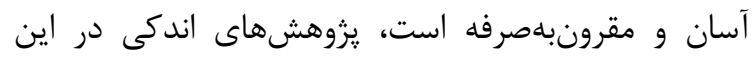

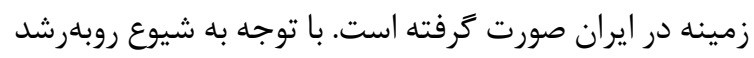

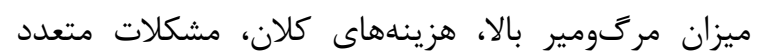

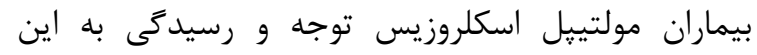
بيماران و تلاش براى كاهش مشكلات و علائم اين بيمارى ضرورى است. بنابراين هدف اين يزوهش تعيين تأثير مشاوره
شخصى، سطح ناتوانى، گروه سنى تحت تأثير، بار اقتصادى

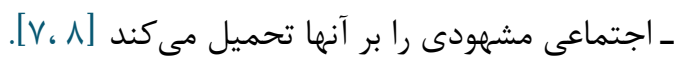

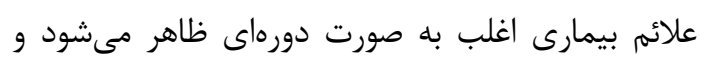

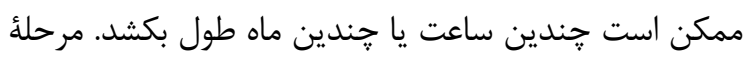
عود بيمارى با التهاب مشخص مىشود و درمان بايد بلافاصله

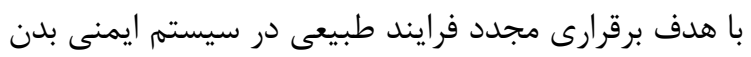

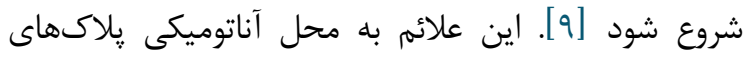

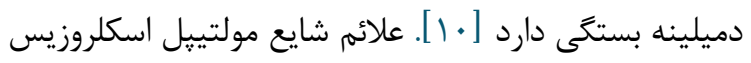

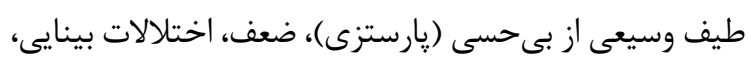

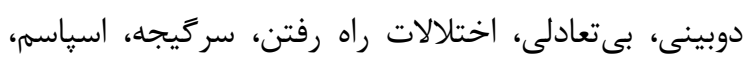

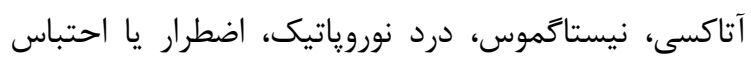

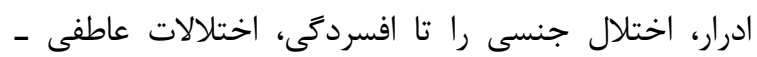

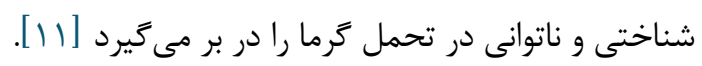

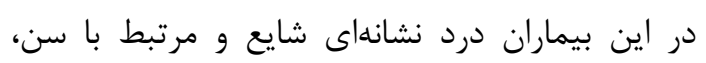

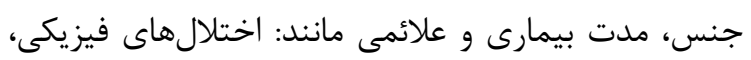
حسى ـ حركتى و شناختى است كه به اختلال خواب،

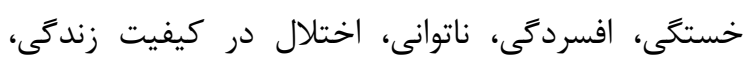

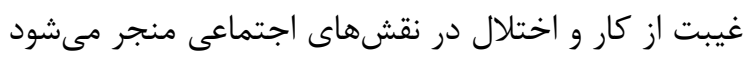

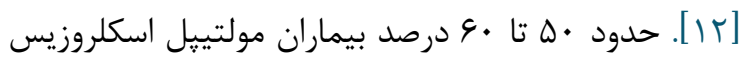

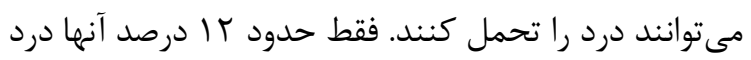

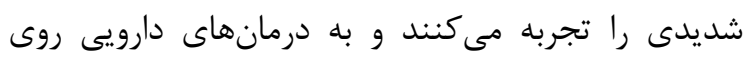

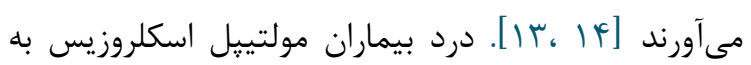
علت آسيب به اعصاب، تخريب غشاهاى عصبى فيبرهاى درد،

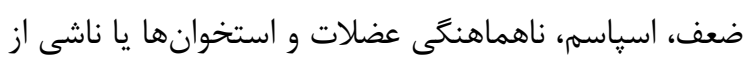

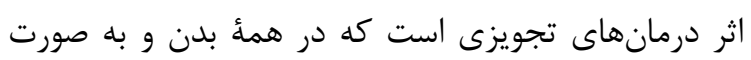

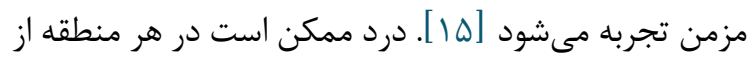

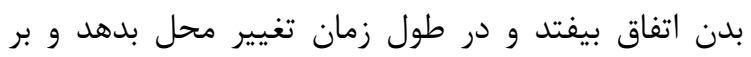

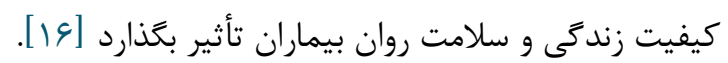

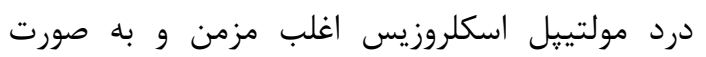

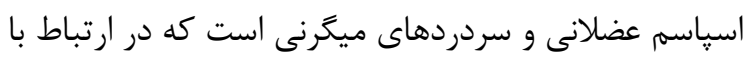

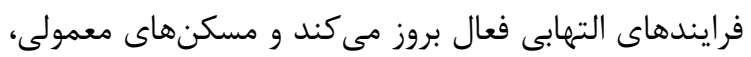

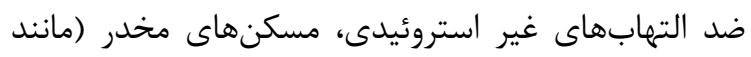

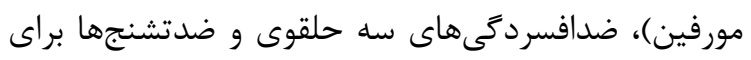

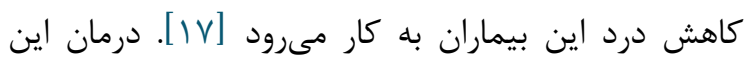

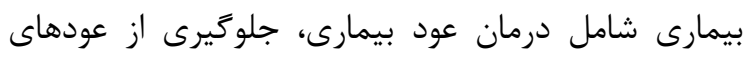
جديد و ويشرفت بيمارى و درمان علائم بيمارى است بـان.

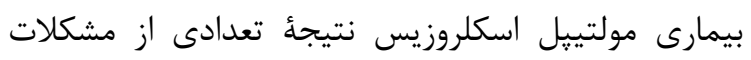


fl أتثير مشاوره همراه با بيخيرى تلفنى بر كاهش شدت درد بيماران

عمومى مربـوط به بيمارى و مقياس ارزيابى سنجش شدت

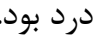

مقياس ارزيابى سنجش درد (Visual Analogue Scale) ابزارى است كه به طور كَترده براى اندازهَيرى ميزان درد

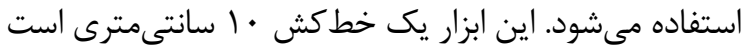

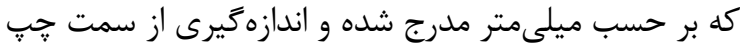

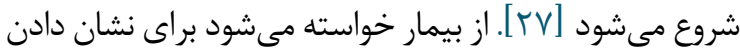
شدت درد دركشده خود از اين ابزار استفاده كند. صفر نبود

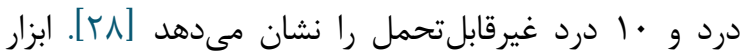

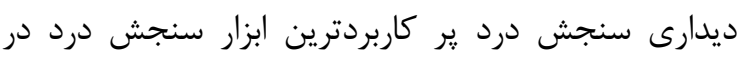

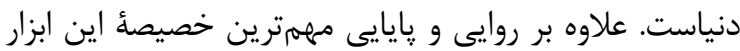

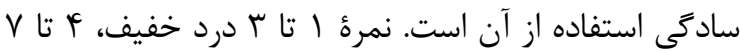

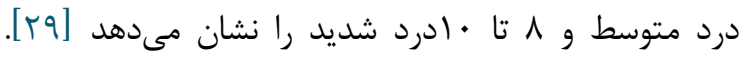
يزوهشهاى متعدد در خارج از كشور روايى و پايايى اين ابزار

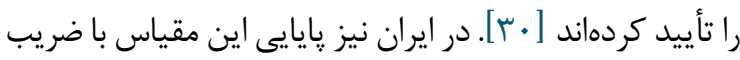

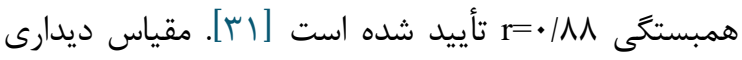
مدرج درد براى سنجش ميزان درد در واحدهاى يزوهش به به

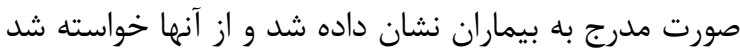
تا ميزان درد خود را بر اساس مقياس مشخص كنند. سيس به آنها توضيح داده شد كه نمرهٔ صفر نبود درد و نمرئ دان

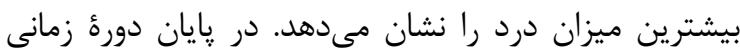

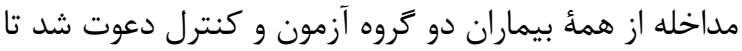
مجددا يرسشنامه سنجش شدت درد را تكميل كنند.

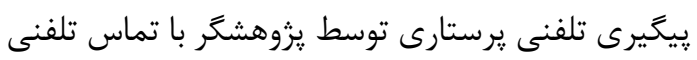

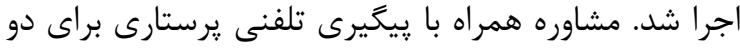

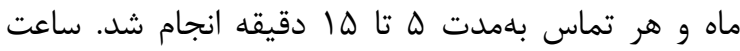

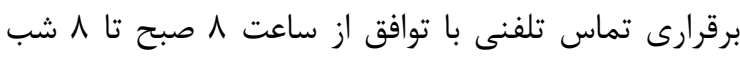

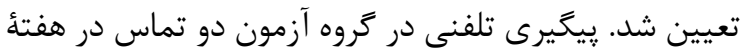

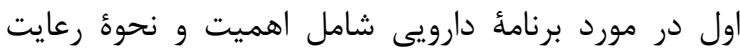

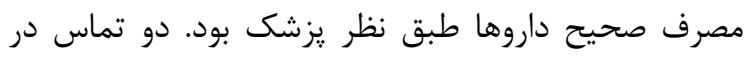

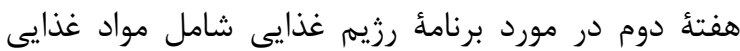
مناسب، اهميت حفظ رزيم غذايى سالم و تغذئ مناسب در

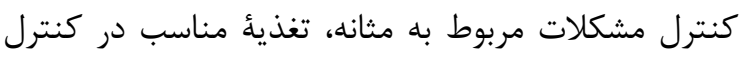

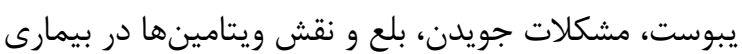
مولتيِل اسكلروزيس بود. دو تماس در هفتهٔ سوم در مورد

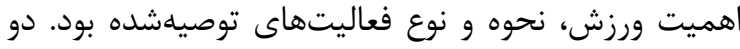

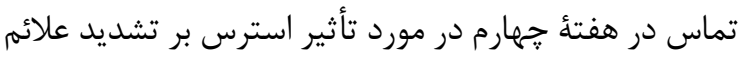

و پيخيرى تلفنى بر كاهش شدت درد بيماران مولتيبل

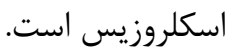

اين يزوهش كارآزمايى بالينى است كه تأثير مشاوره همراه با يُيَيرى تلفنى يرستارى را بر شدت درد بيماران

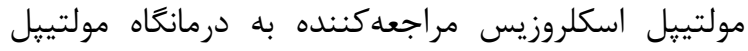
اسكلروزيس بيمارستان فرشجيان سيناى همدان و در فاصلة زمانى خرداد تا شهريور سال وهجا بررسى مى كند. بيماران

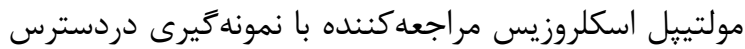
و روش بلوكبندى تصادفى (براى اطمينان از تعداد برابر افراد

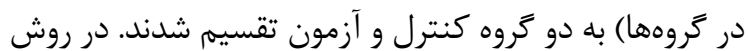

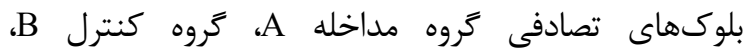
جايگشتهاى مختلف AB ـ به صورت جايگشتهاى تصادفى بلوك هاى جهارتايى AABB، ABBA براى اطمينان از حدس

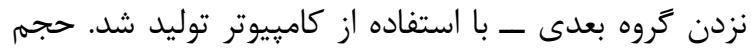

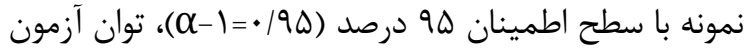

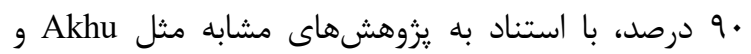

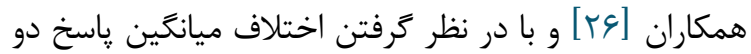

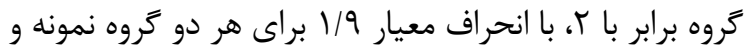

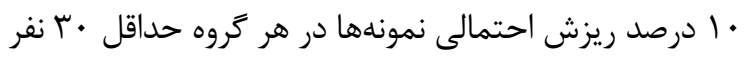

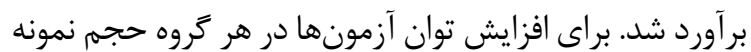
ه广 نفر لحاظ شد (شكل ا، دياكرام كانسورت).

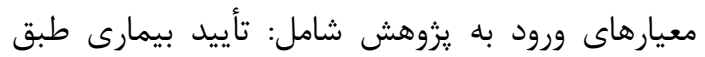
تشخيص متخصص مغز و اعصاب، سن بالاى ^اسال، سابقـ ابتلا به بيمارى حداقل 9 ماه، نبودن در مرحله عود بيمارى، مبتلا نبودن به بيمارى حاد يا مزمن ديكر، دسترسى به تلفن همراه، توانايى صحبت كردن (تكلم و شنوايى) با تلفن همراه، نداشتن زوال عقل و اختلالات شناختهشده روانى تأييدشده توسط يزشك، نمره ميزان ناتوانى برابر يا كمتر از أ با استفاده از مقياس 'EDSS توسط متخصص مغز و اعصاب بود. معيارهاى خروج از يزوهش شامل: ناتوانى بيمار به ادامئ

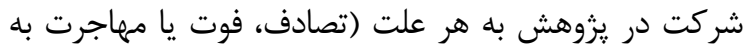

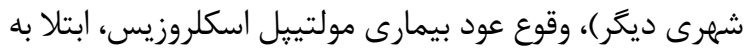
هر بيمارى يا بسترى شدن در طول يزوهش، نداشتن تمايل

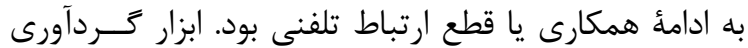

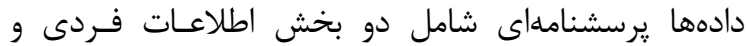

Expanded Disability Status Scale 
على بيكمر ادى و همكاران ها

(آزمونهاى تى زوجى، تى مستقل، كاى دو، آناليز ركرسيون

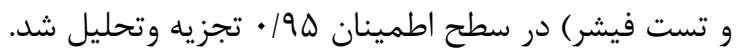

ملاحظات اخلاقى

ملاحظات اخلاقى با ارائهُ توضيحات جامع درباره روش ماتلات

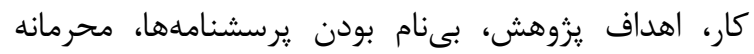

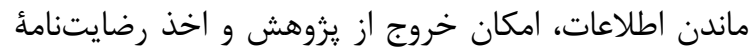

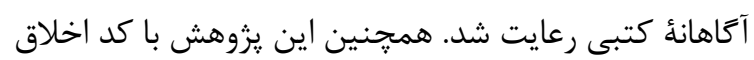
IR.UMSHA.REC.1396.183 در كميتو اخلاق دانشعاه علوم يزشكى همدان تصويب شده است.
بيمارى مولتيِل اسكلروزيس و روشهاى كاهش استرس بود.

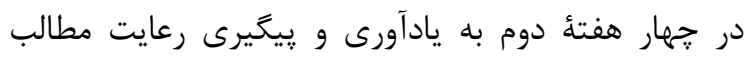

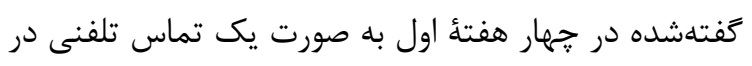
هر هفته بود.

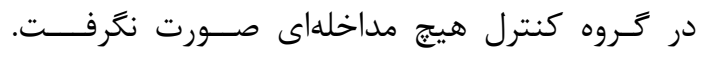

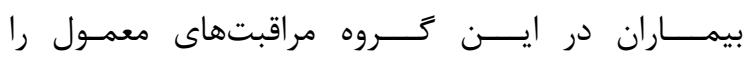
دريافت كردنـد. دادههاى گردآورىشده توسط نرمافزار SPSS نسخئ 91 آ،

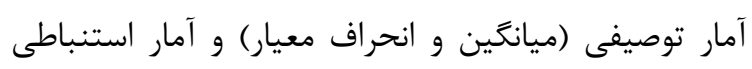

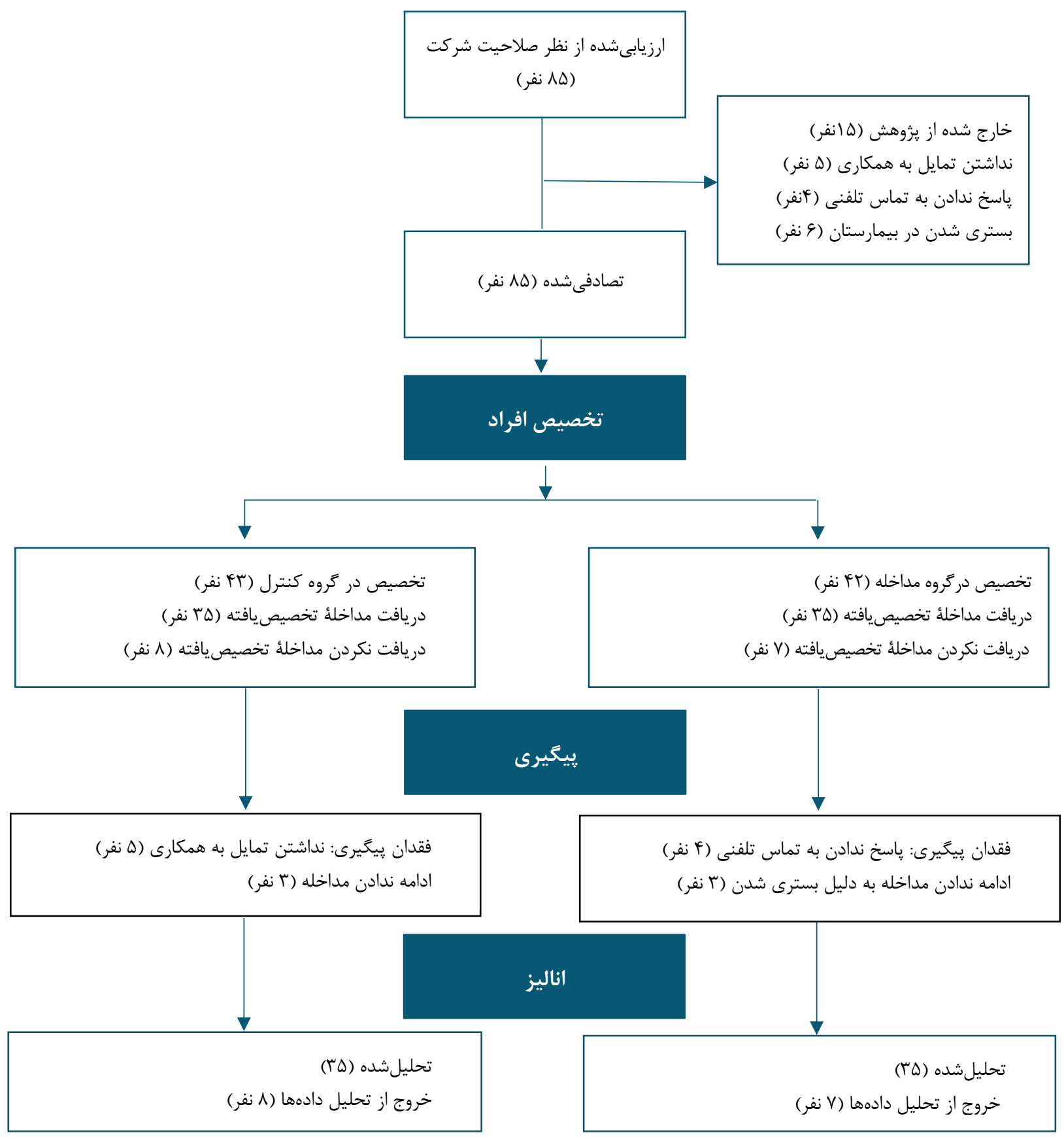

شكل ا. جريان فرايند كنسورت +1+r 


\section{يافته ها}

لحاظ جنس، نوع بيمارى، مدت ابتلا به بيمارى، نوع مسكن دريافتى، دفعات عود و اولين علامت بيمارى نشان نمى بدهدي.

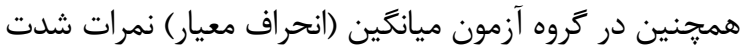

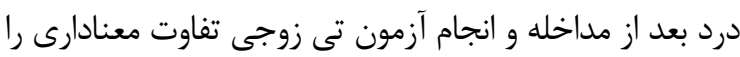

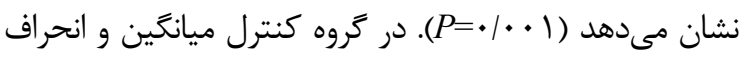
معيار شدت درد بيماران تفاوت معنادارى نداشت، هرجند ميانكين (انحراف معيار) شدت درد در بيماران بعد از مداخله

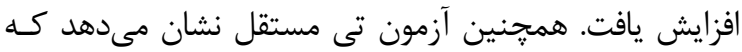

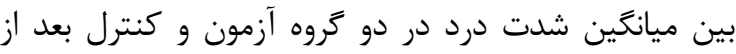

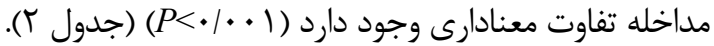

بيماران مولتيبل اسكلروزيس اين يزوهش •r تا • •مساله

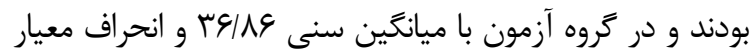
و و در تروه كنترل با ميانكين سنى F/FV

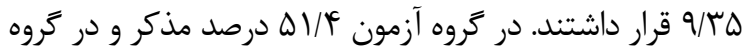

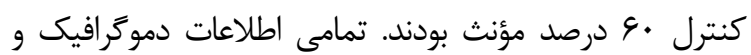
بيمارى بيماران كروه كنترل و مداخله در جدول شماره انشان انشان

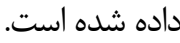

بيماران دو گروه آزمون و كنترل در مشخصات دموكرافيك آنات (سن، شغل و تحصيلات) تفاوت معنادار داشتند، هر جند آزمون

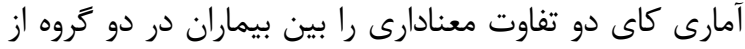

جدول ا. مقايسه مشخصات دموكر افيك و بيمارى بيماران دو گروه كنترل و مداخله مورد مطالعه بر حسب مشخصات دموكَ افيك و بيمارى

\begin{tabular}{|c|c|c|c|c|c|c|}
\hline \multirow{2}{*}{ P-value } & \multicolumn{2}{|c|}{ كنترل } & \multicolumn{2}{|c|}{ آزمون } & \multirow{2}{*}{ متغير } & \\
\hline & 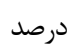 & ت ت تعداد & 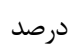 & 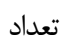 & & \\
\hline \multirow{3}{*}{$P=. / \cdot r q$} & $r$. & v & $r r / q$ & $\wedge$ & $r \cdot-r$. & \multirow{3}{*}{ سن (سال) } \\
\hline & $\mu_{1 / \mathcal{F}}$ & 11 & $\forall \Delta / \Lambda$ & 14 & rI-r. & \\
\hline & FNG & IV & $\mu F / r$ & $\pi$ & $\langle i-\Delta$. & \\
\hline \multirow{2}{*}{$P=\cdot$ V } & ६. & YI & FN/G & IV & مؤنث & \multirow{2}{*}{ جنس } \\
\hline & f. & If & $\Delta 1 / \mathcal{F}$ & 11 & مذكر & \\
\hline \multirow{2}{*}{$P=. / 999$} & $r \Delta / V$ & 9 & $r \Delta / V$ & 9 & مجرد & \multirow{2}{*}{ تأهل } \\
\hline & $V F / T$ & re & $V F / T$ & rq & متأهل & \\
\hline \multirow{4}{*}{$P=\cdot / \cdot \curlyvee \wedge$} & $F \Delta / V$ & 19 & $F r / q$ & 10 & خانهدار & \multirow{4}{*}{ شغل } \\
\hline & $\mid f / 9$ & $\Delta$ & 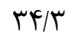 & it & كارمند & \\
\hline & $11 / 4$ & r & $\mid r / \mu$ & $\Delta$ & دانشجو & \\
\hline & TNG & $1 \cdot$ & $N / \Delta$ & r & آزاد & \\
\hline \multirow{3}{*}{$P=\cdot / \cdot 1$} & TNG & $1 \cdot$ & $r \Delta / V$ & 9 & بىسواد & \multirow{3}{*}{ تحصيلات } \\
\hline & $r V / l$ & Ir & r. & If & دييلم & \\
\hline & $r F / r$ & ir & $r F / r$ & ir & 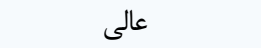 & \\
\hline \multirow{3}{*}{$P=\cdot /$ $\vee \wedge$} & $\Delta F / T$ & 19 & f. & If & يِشرونده - ثانويه & \multirow{3}{*}{ 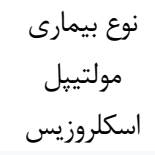 } \\
\hline & $r \mid / F$ & 11 & $\mu F / \mu$ & ir & عودكننده - بهبوديابنده & \\
\hline & $\mid F / \mu$ & $\Delta$ & $r \Delta / V$ & 9 & ي پِيشرونده ـ اوليه & \\
\hline \multirow{3}{*}{$P=. /$ Rtt } & $I V / T$ & 4 & $f \Delta / V$ & 19 & ا تأF سال & \multirow{3}{*}{ مدت ابتلا به } \\
\hline & $F \Delta / V$ & 19 & f. & If & ץ تا م سال & \\
\hline & $r V / l$ & Ir & $\mid F / \mu$ & $\Delta$ & ^ تا ז ا سال & \\
\hline \multirow{4}{*}{$P=\cdot / \Delta V Y$} & $\mu F / \mu$ & IT & $r \cdot / f$ & 11 & ز زلوفن & \multirow{4}{*}{ سكن دريافتى } \\
\hline & TNG & 1. & $r$. & V & استامينوفن & \\
\hline & $r \Delta / \Lambda$ & 9 & $\mathrm{rV} / \mathrm{l}$ & Ir & نايروكسن & \\
\hline & $11 / 4$ & $r$ & $11 / 0$ & r & باكلوفن & \\
\hline \multirow{3}{*}{$P=. / 1 \wedge 9$} & $r F / r$ & Ir & $r \mid / F$ & 11 & بدون عود & \multirow{3}{*}{ دفعات عود } \\
\hline & $\Delta I / F$ & 11 & f. & If & يكبار & \\
\hline & $\Delta / V$ & $r$ & $r r / q$ & $\wedge$ & دو بار & \\
\hline
\end{tabular}




\begin{tabular}{|c|c|c|c|c|c|c|}
\hline \multirow{3}{*}{ P-value } & \multicolumn{2}{|c|}{ كنترل } & \multicolumn{2}{|c|}{ آزمون } & \multirow{2}{*}{\multicolumn{2}{|c|}{ متغير }} \\
\hline & درصد & تعداد & درصد & تعداد & & \\
\hline & NG & r & $\Delta / \Lambda$ & r & سه بار & \\
\hline \multirow{3}{*}{$P=\cdot /$ KY } & TN/G & 1. & $F \Delta / V$ & 19 & حسى & \multirow{3}{*}{ اولين علامت } \\
\hline & 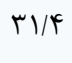 & 11 & $r \Delta / V$ & 9 & حركتى & \\
\hline & f. & If & TN/G & 1. & بينايى & \\
\hline
\end{tabular}

جدول r. مقايسهُ ميانگين شدت درد بيماران مراجعه كننده به درمانكًاه مولتيِل اسكلروزيس بيمارستان فرشجيان سيناى همدان در دو

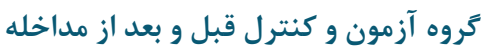

\begin{tabular}{|c|c|c|c|c|c|}
\hline \multirow{2}{*}{ آزمون تى زوجى } & \multicolumn{2}{|c|}{ بعداز مداخله } & \multicolumn{2}{|c|}{ قبل از مداخله } & \multirow{2}{*}{ تروهاها } \\
\hline & انحراف معيار & ميانكين & انحراف معيار & ميانگين & \\
\hline$P=. / . \cdot 1$ & $\cdot / 1 \mathrm{~V}$ & THT & $\cdot / \mu F$ & Q/^६ & آزمون \\
\hline \multirow[t]{2}{*}{$P=\cdot|\Delta V|$} &.$/ 49$ & $\Delta / r)$ & . IFF & $p / r q$ & كنترل \\
\hline & & & & & آزمون تى مستقل \\
\hline
\end{tabular}

مؤثر بين ڤيرستار و بيمار، احساس حمايت از بيمار و تشويق

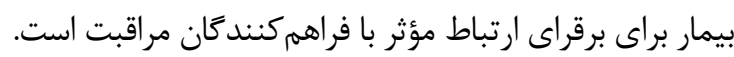

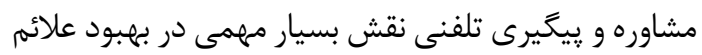

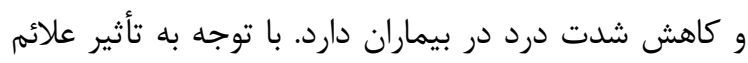

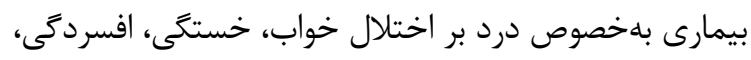

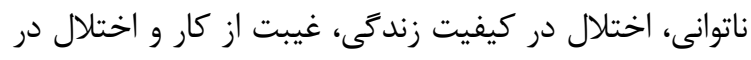
نقشهاى اجتماعى در اين بيماران مشاوره همراه با يِيخيرى تلفنى مىتواند روشى مناسب براى كاهش شدت دئم درد و كنترل

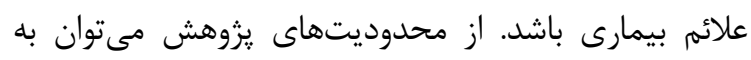

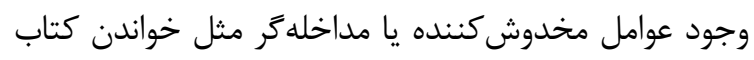

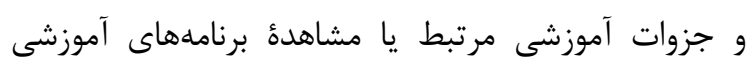

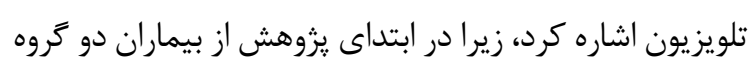
درخواست شده بود تا در دوره زمانى مداخله از مشاهده

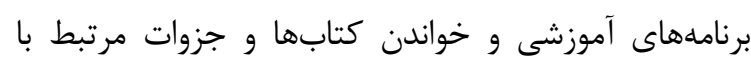

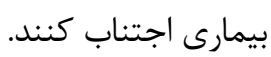$$
\text { نتيجه كيرى }
$$

مشاوره و رييخيرى تلفنى شدت درد بيمـاران را در گروه

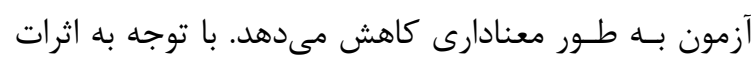

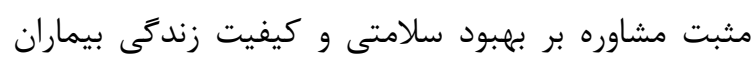

مشاوره همراه با پيخيرى تلفنى بر كاهش شدت درد بيماران

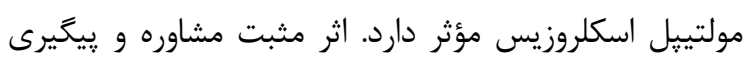

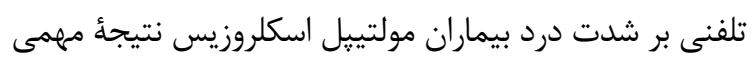
دارد، زيرا درد يكى از مههمترين علائم بيمارى مولتييل

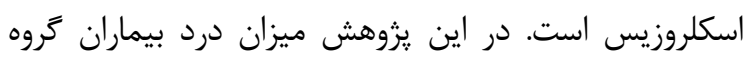

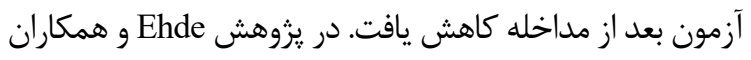

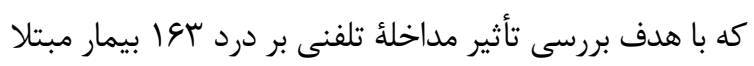

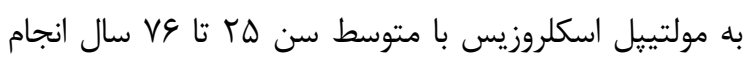
شد، نشان مىدهد مداخلة تلفنى بdمدت 1 هفته درد بيماران

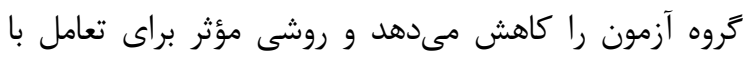

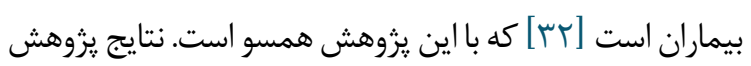
Ikemoto

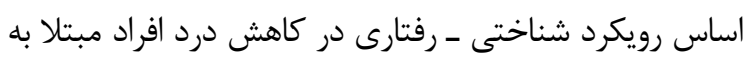

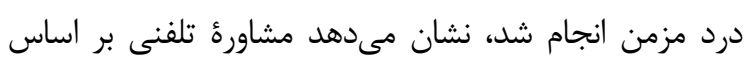

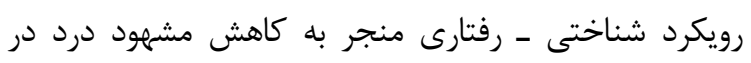
بيماران مىشود [سب]. نكتأُ مشهود اين است كه تأثير مشاوره و يِيخيرى تلفنى بر كاهش شدت درد در زروه آزمون به دليل افزايش و بهبود ارتباط 


$$
\text { 11 تأثير مشاوره همراه با پيخيرى تلفنى بر كاهش شدت درد بيماران }
$$

$$
\begin{aligned}
& \text { كد اخلاق IR.UMSHA.REC.1396.183 ثبت شده است. } \\
& \text { نويسندكان از معاونت يزوهشى دانشعاه علوم يزشكى همدان، } \\
& \text { اعضاى هيئت علمى گروه يرستارى همدان، يرسنل درمانگاه }
\end{aligned}
$$

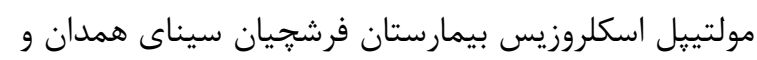

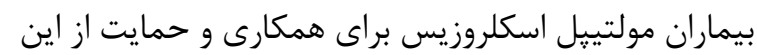

$$
\begin{aligned}
& \text { طرح قدردانى مى كنند. } \\
& \text { تعارض در منافع } \\
& \text { بين نويسندكان هيجز گونه تعارضى در منافع وجود ندارد }
\end{aligned}
$$

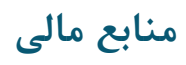

منابع مالى اين مطالعه توسط نويسندكان تامين شده است.

\section{References}

1. Hayes S, Kennedy C, Galvin R, Finlayson M, McGuigan $\mathrm{C}$, Walsh $\mathrm{CD}$, et al. Interventions for Preventing Falls in People with Multiple Sclerosis. 2017. [DOI:10.1002/14651858.CD012475] [PMCID]

2. Mazdeh M, Khazaei M, HASHEMI FN, Ghiasian M. Frequency of Multiple Sclerosis (MS) Among Relatives of MS Patients in Hamadan Society, Iran. Avicenna Journal of Neuro Psych Physiology. 2016;3(1). [DOI:10.17795/ajnpp-38613]

3. Rumah KR, Vartanian TK, Fischetti VA. Oral Multiple Sclerosis Drugs Inhibit the in Vitro Growth of Epsilon Toxin Producing Gut Bacterium, Clostridium Perfringens. Frontiers in cellular and infection microbiology. 2017 Jan 25;7:11. [DOI:10.3389/fcimb.2017.00011] [PMID] [PMCID]

4. Farma BS. Introduction to Multiple Sclerosis 1, Translation Company Bayer Farma Shrink Office. Tehran: Jalal Publication. 2010;1389.

5. Kamm CP, Uitdehaag BM, Polman CH. Multiple Sclerosis: Current Knowledge And Future Outlook. European neurology. 2014;72(3-4):132-41. [DOI:10.1159/000360528] [PMID]

6. Fricska-Nagy Z. New Data in the Epidemiology of Multiple Sclerosis in Hungary (Doctoral dissertation, szte).

7. Thompson AJ, Toosy AT, Ciccarelli O. Pharmacological Management of Symptoms in Multiple Sclerosis: Current Approaches and Future Directions. The Lancet Neurology. 2010 Dec $1 ; 9(12): 1182-99$. 4422(10)70249-0]

[DOI:10.1016/S1474-

8. Jelinek GA, Hassed CS. Managing Multiple Sclerosis in Primary Care: Are We Forgetting Something?. Quality in Primary Care. 2009;17(1):55-61.

9. Wilsdon T, Barron A, Mitchell-Heggs A, Ginoza S. Access to Medicines for Multiple Sclerosis:

$$
\begin{aligned}
& \text { مشاوره همراه با پيخيرى تلفنى براى مدت طولانىتر و مدام }
\end{aligned}
$$

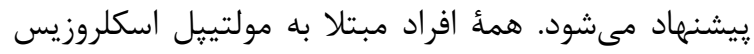

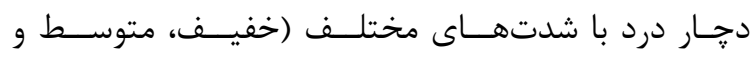

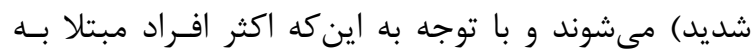

$$
\begin{aligned}
& \text { مولتيِل اسكلروزيس جـوان و جزء نيروهاى كارآمد جامعه }
\end{aligned}
$$

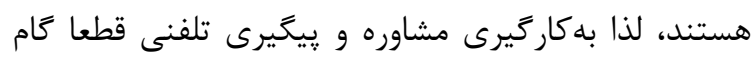

$$
\begin{aligned}
& \text { مـؤثرى در كـاهش درد و بهببود كيفيت زندگَى بيماران است. } \\
& \text { سياسگزارى } \\
& \text { اين مقاله برگرفته از ياياننامهُ كارشناسى ارشد يرستارى }
\end{aligned}
$$

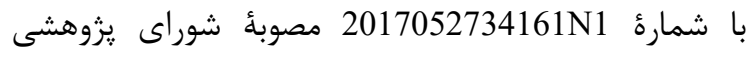

$$
\begin{aligned}
& \text { دانشعاه علوم يزشكى و خدمات بهداشتى ـ درمانى همدان با }
\end{aligned}
$$

Challenges and Opportunities. Report prepared for Biogen Idec. London. 2014 Feb.

10. Metz I, Weigand SD, Popescu BF, Frischer JM, Parisi JE, Guo Y, Lassmann H, Brück W, Lucchinetti CF. Pathologic Heterogeneity Persists in Early Active Multiple Sclerosis Lesions. Annals of neurology. 2014 May;75(5):728-38. [DOI:10.1002/ana.24163] [PMID] [PMCID]

11. Milo R, Miller A. Revised Diagnostic Criteria of Multiple Sclerosis. Autoimmunity reviews. 2014 Apr 1;13(4-5):518-24.

[DOI:10.1016/j.autrev.2014.01.012] [PMID]

12. Heitmann $\mathrm{H}$, Biberacher V, Tiemann L, Buck D, Loleit V, Selter RC, Knier B, Tölle TR, Mühlau M, Berthele A, Hemmer B. Prevalence of Neuropathic Pain in Early Multiple Sclerosis. Multiple Sclerosis Journal. 2016 Aug;22(9):1224-30.Day MA, 13. [DOI:10.1177/1352458515613643] [PMID]

13. Ehde DM, Ward LC, Hartoonian N, Alschuler KN, Turner AP, Kraft GH, Jensen MP. An Empirical Investigation of a Biopsychosocial Model of Pain in Multiple Sclerosis. The Clinical journal of pain. 2016 Feb $1 ; 32(2): 155-63$ [DOI:10.1097/AJP.0000000000000240] [PMID]

14. Fritz NE, Roy S, Keller J, Prince J, Calabresi PA, Zackowski KM. Pain, Cognition and Quality of Life Associate with Structural Measures of Brain Volume Loss in Multiple Sclerosis. NeuroRehabilitation. 2016 Jan 1;39(4):535-44. [DOI:10.3233/NRE-161384] [PMID] [PMCID]

15. Brunner LS. Brunner \& Suddarth's Textbook of Medical-Surgical Nursing. Lippincott Williams \& Wilkins; 2010.

16. Martinelli Boneschi F, Colombo B, Annovazzi P, Martinelli V, Bernasconi L, Solaro C, Comi G. Lifetime and Actual Prevalence of Pain and Headache in Multiple Sclerosis. Multiple Sclerosis Journal. 2008 May;14(4):514-21. [DOI:10.1177/1352458507085551] [PMID]

$$
\text { مجله مراقبت يرستارى و مامايى ابنسينا }
$$


17. Khan N, Smith MT. Multiple Sclerosis-Induced Neuropathic Pain: Pharmacological Management and Pathophysiological Insights from Rodent EAE Models. Inflammopharmacology. 2014 Feb 1;22(1):122. [DOI:10.1007/s10787-013-0195-3] [PMID] [PMCID]

18. Kes VB, Cengić L, Cesarik M, Tomas AJ, Zavoreo I, Matovina LZ, Corić L, Drnasin S, Demarin V. Quality of Life in Patients with Multiple Sclerosis. Acta clin croat. 2013 Mar 1;52(1):107-1.

19. Poser CM. The Diagnosis and Management of Multiple Sclerosis. Acta neurologica scandinavica. 2005 Sep;112(3):199-201. [DOI:10.1111/j.16000404.2005.00450.x] [PMID]

20. Schlachta-Fairchild L, Varghese SB, Deickman A, Castelli D. Telehealth and Telenursing are Live: APN Policy and Practice Implications. The journal for nurse practitioners. $2010 \quad$ Feb 1;6(2):98-106. [DOI:10.1016/j.nurpra.2009.10.019]

21. Kumar S, Snooks H, editors. Telenursing. Springer Science \& Business Media; 2011 Jul 9. [DOI:10.1007/978-0-85729-529-3]

22. Peck A. Changing the Face of Standard Nursing Practice Through Telehealth and Telenursing. Nursing administration quarterly. 2005 Oct 1;29(4):339-43. [DOI:10.1097/00006216-200510000-00008] [PMID]

23. Collaborative OC. Chronic Obstructive Pulmonary Disease (COPD) Evidentiary Framework. Ontario health technology assessment series. 2012;12(2):1.

24. Hsu YC, Tsai CH, Kuo YM. Telecare Services for Elderly: Predictive Factors of Continued Use Intention. The open biomedical engineering journal. 2016;10:82. [DOI:10.2174/1874120701610010082] [PMID] [PMCID]

25. Kalankesh LR, Pourasghar F, Nicholson L, Ahmadi S, Hosseini M. Effect of Telehealth Interventions on Hospitalization Indicators: A Systematic Review. Perspectives in health information management. 2016;13(Fall).

26. Akhu-Zaheya LM, Wa'ed YS. The Effect of Short Message System (SMS) Reminder on Adherence to a Healthy Diet, Medication, and Cessation of Smoking Among Adult Patients with Cardiovascular Diseases. International journal of medical informatics. $2017 \mathrm{Feb}$ 1;98:65-75. [DOI:10.1016/j.ijmedinf.2016.12.003] [PMID]

27. Myles PS, Troedel S, Boquest M, Reeves M. The Pain Visual Analog Scale: Is It Linear or Nonlinear?. Anesthesia \& Analgesia. 1999 Dec 1;87(6):1517. [DOI:10.1213/00000539-199912000-00038]

28. Loos MJ, Houterman S, Scheltinga MR, Roumen RM. Evaluating Postherniorrhaphy Groin Pain: Visual Analogue or Verbal Rating Scale?. Hernia. 2008 Apr 1;12(2):147-51. [DOI:10.1007/s10029-007-0301-9] [PMID]

29. Mendelson G, Selwood TS. Measurement of Chronic Pain: A Correlation Study of Verbal and Nonverbal Scales. Journal of behavioral assessment. 1981 Dec 1;3(4):263-9. [DOI:10.1007/BF01350830]
30. Vickers ER, Cousins MJ, Woodhouse A. Pain Description and Severity of Chronic Orofacial Pain Conditions. Australian dental journal. 1998 Dec;43(6):403-9. [DOI:10.1111/j.18347819.1998.tb00200.x] [PMID]

31. Rezvani Amin M, Siratinayer M, Abadi A, Moradyan T. Correlation Between Visual Analogue Scale and Short Form of McGill Questionnaire in Patients with Chronic Low Back Pain. Qom University of Medical Sciences Journal. 2011 Apr 10;5(1):31-4.

32. Ehde DM, Elzea JL, Verrall AM, Gibbons LE, Smith AE, Amtmann D. Efficacy of a Telephone-Delivered Self-Management Intervention for Persons With Multiple Sclerosis: A Randomized Controlled Trial with a One-Year Follow-Up. Archives of physical medicine and rehabilitation. 2015 Nov 1;96(11):194558. [DOI:10.1016/j.apmr.2015.07.015] [PMID]

33. Ikemoto K, Yamagata Y, Ikemoto T, Kawai T, Aono $\mathrm{S}$, Arai YC. Telephone Consultation Partially Based on a Cognitive-Behavioral Approach Decreases Pain and Improves Quality of Life in Patients with Chronic Pain. Anesthesiology and pain medicine. 2015 Dec;5(6). [DOI:10.5812/aapm.32140] [PMID] [PMCID] 